\title{
Synthesis of Inconel 718 Superalloy by Electric Current Activated Sintering
}

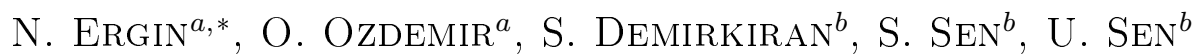 \\ ${ }^{a}$ Sakarya University, Technology Faculty, Department of Metallurgy and \\ Materials Engineering, 54187, Esentepe Campus, Sakarya-Turkey \\ ${ }^{b}$ Sakarya University, Engineering Faculty, Department of Metallurgy and \\ Materials Engineering, 54187, Esentepe Campus, Sakarya-Turkey
}

\begin{abstract}
In the present study, the production of Inconel 718 nickel based superalloy was carried out in an electric current activated sintering in open air under a uniaxial pressure of $300 \mathrm{MPa}$ using $\mathrm{Al}, \mathrm{Ni}, \mathrm{Fe}, \mathrm{Cr}, \mathrm{Ti}, \mathrm{Co}, \mathrm{Fe}-\mathrm{Nb}$ and $\mathrm{Fe}-\mathrm{Mo}$ powders. This alloy was heat treated, following the conventional treatment which consists of a $1 \mathrm{~h}$ solution treated at $980{ }^{\circ} \mathrm{C}$, followed by air cooling and double ageing, $8 \mathrm{~h}$ at $720^{\circ} \mathrm{C}$, furnace cooling at $55^{\circ} \mathrm{C} / \mathrm{h}$ down to $620^{\circ} \mathrm{C}$ and ageing for $8 \mathrm{~h}$. Optical and SEM examinations showed a dense microstructure with low amount of porosity. XRD studies showed the existence of the $\gamma$ and MC type carbide ( $\mathrm{M}$ atom is a Nb, Ti combination) and $\delta$ phases. The relative density of sample measured according to Archimedes' principle was $93.7 \%$, and the microhardness of sample was about $343.8 \mathrm{HV}_{0.1}$.
\end{abstract}

DOI: 10.12693 /APhysPolA.127.1100

PACS: 81.05.Bx, 81.20.Ev, 81.40.Cd

\section{Introduction}

Superalloys are high temperature materials which are used widespread in many industries, especially in several engine components in gas turbines utilized for electricity production, marine applications, and aircrafts. This is due to the fact that they have excellent high temperature strength and corrosion resistance. Among the superalloys, Inconel 718 is a nickel base superalloy strengthened primarily by ordered body centred tetragonal (BCT) $\gamma^{\prime \prime}-\mathrm{Ni}_{3} \mathrm{Nb}$ and ordered face centred cubic (FCC) $\gamma^{\prime}-\mathrm{Ni}_{3}(\mathrm{Al}, \mathrm{Ti})$-precipitates. In 718 is largely used in the fabrication of critical pieces for turbine engines because of its high mechanical properties (yield strength up to $650^{\circ} \mathrm{C}$, impact strength and fracture toughness down to $-40^{\circ} \mathrm{C}$ ), as well as good corrosion resistance. It is generally processed through conventional ingot metallurgy route and is available in the bar and sheet forms. Several advanced melting and casting techniques have been developed for this alloy, but the melt related problems such as macro-segregation, formation of freckles, laves phase and white spots leading to large scatter in the mechanical properties could not completely be avoided in wrought products made from big ingots. To meet the present requirements of high fatique strength and lightweight combination, a great demand exists for new processing methods for alloy 718 [1-6].

Electric Current Activated Sintering (ECAS) is a new class of consolidation methods in which mechanical pressure is combined with electric and thermal fields to enhance interparticle bonding and densification. This tech-

*corresponding author; e-mail: nergin@sakarya.edu.tr nique, loose powders or a cold formed compact to be consolidated are inserted into a container which is heated to and then held at the desired temperature, while pressure is applied and maintained for a given period of time. Heat is provided by passing an electric current through the powders and/or their container, thus exploiting the consequent Joule effect. This technology is characterized by technological and economic advantages over conventional sintering methods such as faster heating rate, lower sintering temperature, shorter holding time, consolidation of difficult-to-sinter powders, elimination of the need of sintering aids, no need of cold compaction, less sensitivity to initial powders characteristics, and marked comparative improvements in the properties of materials consolidated $[7,8]$.

In this work, Inconel 718 superalloy was produced by ECAS method and their properties were also investigated using various techniques including optical microscopy (OM), scanning electron microscopy (SEM-EDS) and Xray difraction (XRD). In order to determine hardness and density of the test materials, a Vickers indenter and Archimedes' technique were utilized.

\section{Experimental details}

In order to manufacture Inconel 718 superalloy as starting materials Co powder (99.9\% purity, $10 \mu \mathrm{m}), \mathrm{Fe}$ powder (99.9\% purity, 1-9 $\mu \mathrm{m}$ ), Al powder (99\% purity, $15 \mu \mathrm{m})$, Ni powder $(99.8 \%$ purity, $3-7 \mu \mathrm{m})$, Ti powder $(99.5 \%$ purity, less than $44 \mu \mathrm{m})$, Cr powder $(99.8 \%$ purity, $1-5 \mu \mathrm{m}$ ), Fe-Nb powder (70\% purity, less than $38 \mu \mathrm{m}$ ) and Fe-Mo powder (65\% purity, less than $38 \mu \mathrm{m}$ ) were used. Their chemical compositions are given in Table I. These powders were mixed in stoichiometric ratio corresponding to the Inconel 718 material. The production of samples was performed by electric current activated sintering. In order to balance the strength and duc- 
tility, the produced sample was given the standard heat treatment solution treatment at $980^{\circ} \mathrm{C}$ for $1 \mathrm{~h} /$ water quenched to room temperature and a two-step ageing treatment consisting of $720^{\circ} \mathrm{C}$ for $8 \mathrm{~h}$ /furnace cooling at $55^{\circ} \mathrm{Ch}^{-1}$ to $620^{\circ} \mathrm{C}$ and holding at $620^{\circ} \mathrm{C}$ for $8 \mathrm{~h}$ before air cooling to room temperature.

Chemical composition of Inconel 718 TABLE I superalloy.

\begin{tabular}{c|c|c|c|c|c|c|c|c|c}
\hline \hline $\mathrm{Fe}$ & $\mathrm{Cr}$ & $\mathrm{Ni}$ & $\mathrm{Nb}$ & $\mathrm{Mo}$ & $\mathrm{Al}$ & $\mathrm{Ti}$ & $\mathrm{Co}$ & $\mathrm{C}$ & $\mathrm{Si}$ \\
\hline \multirow{2}{*}{ Balance } & $17-$ & $50-$ & $4.7-$ & $2.8-$ & $0.2-$ & $0.65-$ & $0.2-$ & $0.03-$ & \\
& 20 & 55 & 5.5 & 3.3 & 0.8 & 1.15 & 0.5 & 0.06 & 0.22
\end{tabular}

The relative density and porosity of the synthesized sample were measured using Archimedes' method. The microstructures and phase distribution were characterized by optical microscopy (OM), scanning electron microscopy (SEM-EDS) and X-ray diffraction (XRD). Microhardness of sintered test materials was determined by using micro-hardness tester with a load of $100 \mathrm{~g}$ for $15 \mathrm{~s}$ on polished cross-sectional area of test materials.

\section{Results and discussion}

The microstructures of Inconel 718 superalloy produced by electric current activated sintering method was examined by optical (OM) and scanning electron microscopy (SEM) examinations (Fig. 1a, 1b). SEM and optical microstructural analysis studies showed that the in test materials phase transformation has been completed and a dense microstructure with very low amount of porosity were determined. There are three kinds of thermomechanical treatment techniques according to the structure and properties of Inconel 718 alloy required in different service conditions: standard aging (STD), high strength aging (HS) and double aging (DA), among which DA is the most important technique. The components made by DA technique have fine and homogenous grains, very high strength, good ductility, low-cycle fatigue (LCF) and the ability of anti-crack extension.In Inconel 718 alloy the $\delta$ phases can precipitate along grain boundary through DA technique which is beneficial to restrain the extension of cracks in grain. On the other hand, the contents of element-Nb can be consumed with the precipitating of $\delta$ phases, leading to the occurrence of depleted zone for $\gamma^{\prime}$ and $\gamma$ phase around the precipitates of $\delta$ phases [9].

Figure 2 shows the X-ray diffraction pattern of Inconel 718 alloy with DA techniques. The presence of the MC, $\delta$ and $\gamma$ phases can be clearly identified from their diffraction peaks. The $\gamma$ phase (111) $(2 \theta-43.47)$, (200) $(2 \theta-50.57),(220)(2 \theta-74.54)$ diffraction peaks can be observed. The $\gamma^{\prime \prime}$ and $\gamma^{\prime}$ phases diffraction peak are very close to the $\gamma$ phase's diffraction peak. The $\gamma^{\prime \prime}$ phase is $\mathrm{DO}_{22}$ structure, and the $\gamma^{\prime}$ phase is $\mathrm{Ll}_{2}$ structure. The lattice parameter of $\gamma^{\prime \prime}$ phase is $a=0.3624 \mathrm{~nm}$ and $c=0.7406 \mathrm{~nm}$, and the lattice parameter of $\gamma^{\prime}$ phase is $0.3590 \mathrm{~nm}$. The diffraction plane, interplanar spacing, diffraction angle and relative intensity of $\gamma^{\prime \prime}, \gamma^{\prime}$ phases are given in Table II [10].

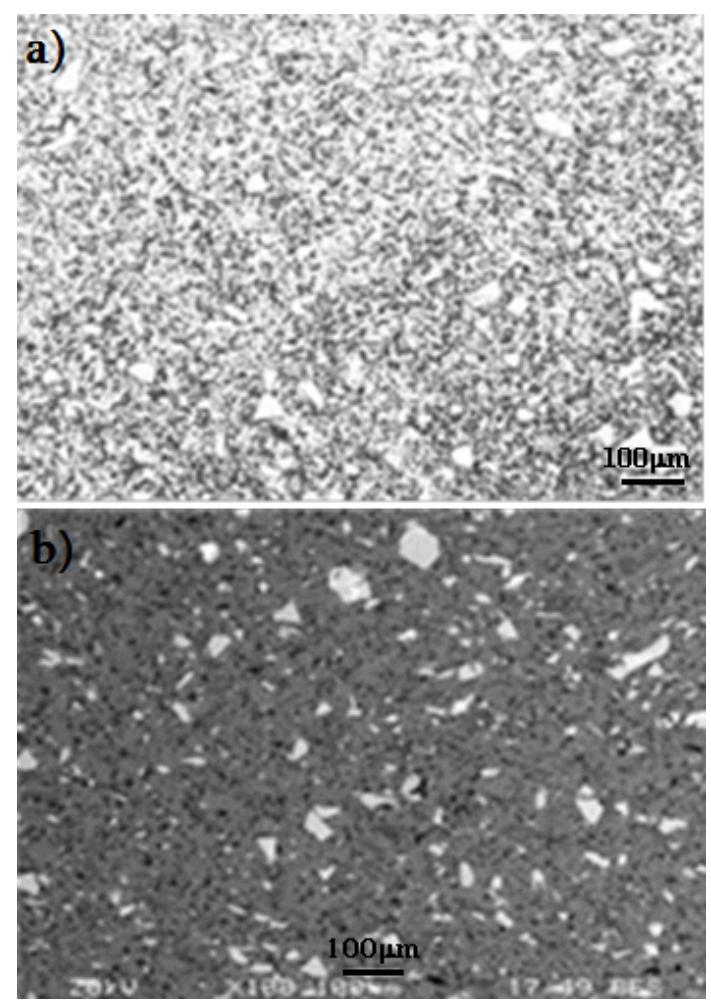

Fig. 1. (a) Optic and (b) SEM images of sample.

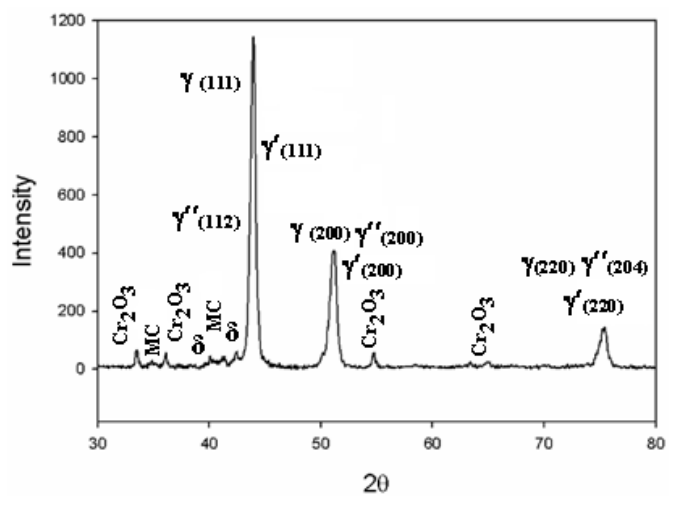

Fig. 2. X-ray diffraction pattern of sample.

Diffraction plane $(h k l)$, interplanar spacing $(d)$, diffraction angle $(2 \theta)$ and relative intensity $(I)$ of $\gamma$ and $\gamma^{\prime}$ phases [10].

\begin{tabular}{c|c|c|c|c|c|c|c}
\hline \hline \multicolumn{5}{c|}{$\gamma^{\prime \prime}$ phase } & \multicolumn{4}{c}{$\gamma^{\prime}$ phase } \\
\hline$h k l$ & $d$ & $2 \theta$ & $\mathrm{I}$ & $h k l$ & $d$ & $2 \theta$ & $\mathrm{I}^{a}$ \\
\hline 101 & 3.262 & 27.34 & 5 & $100^{5}$ & 3.600 & 24.73 & $\mathrm{~W}$ \\
110 & 2.561 & 35.04 & 1 & $110^{5}$ & 2.546 & 35.26 & $\mathrm{~W}$ \\
112 & 2.107 & 42.92 & 100 & 111 & 2.079 & 43.54 & $\mathrm{VS}$ \\
103 & 2.040 & 44.41 & - & 200 & 1.800 & 50.72 & $\mathrm{~S}$ \\
004 & 1.852 & 49.20 & 16 & $210^{5}$ & 1.610 & 57.22 & $\mathrm{VW}$ \\
200 & 1.812 & 50.36 & 31 & $211^{5}$ & 1.470 & 63.28 & $\mathrm{VW}$ \\
202 & 1.627 & 56.57 & 1 & 220 & 1.273 & 74.56 & $\mathrm{~S}$ \\
211 & 1.587 & 58.13 & 1 & $300^{5}$ & 1.200 & 79.95 & $\mathrm{VW}$ \\
204 & 1.294 & 73.13 & 18 & $310^{5}$ & 1.138 & 85.25 & $\mathrm{VW}$ \\
\hline
\end{tabular}

$\mathrm{I}^{a}$ - VS: very strong, S: strong, W: weak, VW: v. weak 

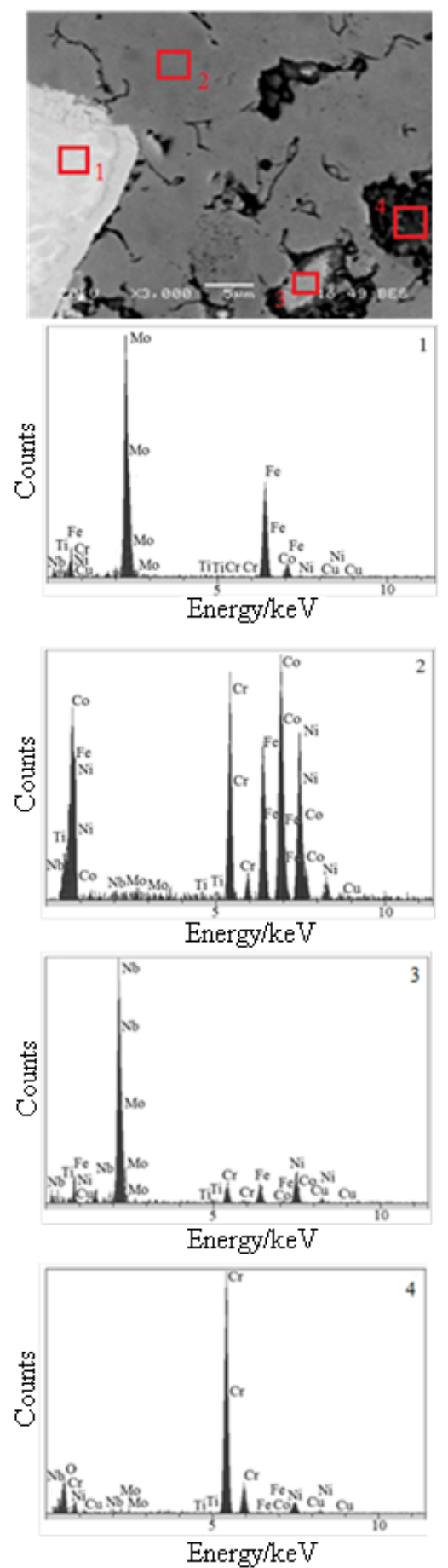

Fig. 3. EDS analysis of sample.

Wang and $\mathrm{Li}[9]$ pointed out that in Inconel 718 ally via $\mathrm{DA}$ at $720^{\circ} \mathrm{C} / 8 \mathrm{~h}+620^{\circ} \mathrm{C} / 8 \mathrm{~h}$ can distribute both $\gamma^{\prime}$ and $\gamma$ phases with disc shape in the matrix, most of $\delta$ phases form discontinuous stick shape and only a small amount of granular $\delta$ phases precipitate along grain boundary. It is composed of $\gamma$ matrix, MC, $\gamma^{\prime}, \gamma$ and $\delta$ phases, among which $\gamma^{\prime \prime}$ phase plays a main role in strengthening the alloy, and $\gamma^{\prime}$ phase, less than $\gamma^{\prime \prime}$ phase in contents, also strengthens the alloy to a certain extent, however, the existences of $\delta$ phases are disadvantageous to the mechanical properties of alloy. The mechanical properties of this alloy depend significantly on the contents and shape of $\gamma^{\prime}, \gamma$ and $\delta$ phases. It is clear that both the contents and shape of $\gamma^{\prime}, \gamma$ and $\delta$ phases can change under different treatment techniques, leading to different mechanical properties of alloy. The distribution of alloying elements in the samples was determined by EDS analysis as shown in Fig. 3. According to the analyses, it was observed that white region of Fe-Mo based phases (Mark 1), matrix of Co-Cr-Ni-Fe based phases (Mark 2), grey region of Nb-based phases (Mark 3) and dark region of chromium oxide (Mark 4) were observed from analyses. The hardness of produced Inconel 718 samples measured using Vickers indentation technique with a load of $100 \mathrm{~g}$ was approximately $343.8 \mathrm{HV}_{0.1}$. According to literature, hardness values of the Inconel 718 superalloys as depending on heat treatment temperature and ageing time are in the range of $30-40 \mathrm{HR}_{C}(300-390 \mathrm{HV})$. The hardness result of present study agree with previous other works. The relative density of the samples calculated according to Archimedes' principle was approximately $93.7 \%$.

\section{Conclusions}

Inconel 718 superalloy produced by electric current activated sintering has low porosity. The presence of $\gamma$ the, $\mathrm{MC}$ type carbide ( $\mathrm{M}$ atom is a $\mathrm{Nb}, \mathrm{Ti}$ combination) and $\delta$ phases were identified by XRD analysis. The relative density is $93.7 \%$ for Inconel 718 superalloys. The microhardness of materials measured by Vickers indenter of the sample was about $343.8 \mathrm{HV}_{0.1}$.

\section{Acknowledgments}

This work was supported by the Sakarya University Scientific Research Foundation (Project Number: 201005-06-014).

\section{References}

[1] C. Slama, M. Abdellaoui, Journal Of Alloys And Compounds 306, 277 (2000).

[2] G. Rao, M. Kumar, M. Srinivas, D.S. Sarma, Materials Science and Engineering A 355, 114 (2003).

[3] G.A. Rao, M. Srinivas, D.S. Sarma, Materials Science and Engineering A 383, 201 (2004).

[4] Y.C. Chen, Y.S. Liao, Journal of Materials Processing Technology 140, 269 (2003).

[5] M.S. Kasım, C.H. Haron, J.A. Ghani, M.A. Sulaiman, M.Z.A. Yazıd, Wear 302, 1171 (2013).

[6] A. Altıncekic, Master Thesis "Evolution Of Precipitate Microstructure In The Superalloy In7381C During Compression Creep", Boğaziçi University, 2008.

[7] S. Grasso, Y. Sakka, G. Maizza, Sci. Technol. Adv. Mater. 10, 1 (2009).

[8] R. Orru, R. Licheri, A.M. Locci, A. Cincotti, G. Cao, Materials Science and Engineering R63, 127 (2009).

[9] C. Wang, R. Li, Journal Of Materials Science 39, 2593 (2004).

[10] W.C. Liu, M. Yao, Z.L. Chen, S.G. Wang, Journal Of Materials Science 34, 2583 (1999). 